\title{
Oh, Behave: When Wildlife Behavior Matters in Conservation
}

\author{
RACHEL N. CABLE \\ Volume 1, Fall 2013 \\ DOI: http://dx.doi.org/10.3998/mjs.12333712.0001.013
}

The establishment and maintenance of modern sustainability require societies to address the current impacts of humans on the natural world, including the impacts of human presence on wildlife. The most frequently considered anthropogenic effects on wildlife include direct overexploitation through hunting and fishing and indirect exploitation through the removal of resources or habitats that wildlife species rely upon. Indeed, these drivers typically lead to declines in wildlife numbers and thus attract the focus of many conservation studies and management strategies. Sometimes, however, species may not altogether disappear from an area or rapidly decline in population size, but they are still affected by human presence. The subtler outcomes of human-wildlife interactions include, but are not restricted to, disease transfer, conflict between groups (Sillero-Zubiri, Sukumar, and Treves 2007), and alterations in wildlife behavior (Beale 2007). These aspects are difficult to study but important to understand for effective implementation of conservation measures and coexistence between humans and wildlife. Conservationists and ethologists have recently realized that animal behavior in particular plays a more important role in conservation than previously recognized, and behavioral effects are becoming a focus in management techniques (Caro 1999; Sutherland 1998; Swaisgood 2007; Swaisgood 2010).

When wildlife species directly interact with humans, or even indirectly interact via human-altered habitats, individual animals may modify their behavior to minimize perceived risks (Frid and Dill 2002; Tuomainen and Candolin 2011; Beale 2007; Beale and Monaghan 2004). For instance, many ungulates will flee at the approach of a human and are especially wary in highly disturbed areas (Stankowich 2008); migratory animals such as African elephants (Loxodonta africana) and migratory 
birds such as the common crane (Grus grus) consistently choose migratory paths and stop-over sites with little human disturbance (Graham et al. 2009; Végvári et al. 2011). Such behaviors can become costly for individual animals and their populations. For instance, a wary animal avoiding encounters with humans must budget more time to energetically expensive activities such as travelling and vigilance, which detracts from time spent on other necessary activities, such as searching for food or mates and raising young (Frid and Dill 2002; Beale 2007; Stankowich 2008). In fact, killer whales (Orcinus orca) significantly reduce their foraging time in the presence of boats (Williams, Lusseau, and Hammond 2006; Lusseau et al. 2009), and Amur tigers (Panthera tigris altaica) spend less time at kills and consume less meat when disturbed by humans (Kerley et al. 2002). Although these changes in energetic budgets may seem temporary and of little impact, when they occur frequently they can affect the survival and reproduction of individuals, as well as the effective population size of species (Anthony and Blumstein 2000). Such effects are a concern not only for currently threatened species, but also for species in areas where human populations, and thus encounters with humans, will increase.

Studies concerning anthropogenic effects on wildlife behavior are important both in their own right and for their unique contribution to effective conservation strategies (Caro 1999; Sutherland 1998; Berger-Tal et al. 2011). Behavioral data from areas of low disturbance can serve as a baseline of comparison for behaviors in disturbed areas and as standards for individuals in captive breeding programs. For example, an understanding of how wild animals select habitats in undisturbed areas allows conservationists to effectively create protected areas and release individuals in captive breeding programs in preferred habitats, thus increasing the chances of species survival (Swaisgood 2007; Indermaur and Schmidt 2011). Protected areas such as national parks become integral for observing the species, processes, and interactions that are otherwise altered, unobservable, or nonexistent in areas manipulated by humans (Davis, Graber, and Acker 2004). Alternatively, in areas of moderate to high disturbance, behavioral studies can help assess the degree and complexity of anthropogenic impacts as well as aid in designing management decisions. An understanding of animal ranging across large areas, for instance, informs preserve design and possible optimization of connectivity between preserves (Reed 2002). Along these lines, protected areas with high levels of human disturbance offer unique opportunities for research to directly influence management policies within focal preserves or parks, as well as in similar ecosystems outside the protected areas (Parsons 2004; Ramirez 2004). For instance, the effects of recreation and tourism on wildlife have become a concern in many protected areas. Thus, researchers are now perform- 
ing studies to quantify these effects, such as observing the minimum distance from humans tolerated by large ungulates (Malo, Acebes, and Traba 2011; Stankowich 2008), or the maximum number of boats tolerated by marine animals (Williams and Ashe 2007). These studies are highly informative in the creation of park regulations that protect animals from behavioral disturbances, while allowing visitors to observe the animals they have come to see.

My research falls at this intersection of animal behavior and conservation. In particular, I study the impacts of human presence on the gelada (Theropithecus gelada), a primate species, in the Simien Mountains National Park, Ethiopia. The park encompasses 23,000 ha of prime gelada habitat: steep cliffs and mountaintop plateaus ranging from 2,350 to $4,000 \mathrm{~m}$ in elevation. The landscapes created by the topography of the park, as well as the unique biodiversity within the park, inspired UNESCO to inscribe the area as a World Heritage Site in 1978 (Debonnet, Melamari, and Bomhard 2006). Many of the species found in the park are endemic, or especially adapted to this high-altitude environment, and are found only in the Ethiopian highlands (Harmsen, Spence, and MaHaney 1991; Debonnet, Melamari, and Bomhard 2006). In fact, Ethiopia first established the park in 1969 to protect the only remaining population of the Walia ibex (Capra walie), a mountain goat on the brink of extinction (Debonnet, Melamari, and Bomhard 2006). Other notable wildlife species endemic to the Ethiopian highlands found in the park include the most endangered canid in the world, the Simien wolf (Canis simiensis) (Yihune, Bekele, and Tefera 2008), and the only officially protected population of geladas. Geladas are unique primates in that they are terrestrial, eat grass, and travel in groups of up to 900 individuals across the mountaintop plateaus (Kawai 1983; Iwamoto 1993), making them the easiest wildlife species to track and follow in the park. These traits and others, such as a large vocal repertoire and a conspicuous patch of bare skin on its chest that may indicate fertility or status, make the gelada a prime study species. My research was conducted in conjunction with the University of Michigan Gelada Research Project and complements other ongoing studies on gelada behavior (Roberts et al. 2012; Bergman 2013), sociality (Snyder-Mackler, Beehner, and Bergman 2012), endocrinology (Beehner and McCann 2008), and genetics (Snyder-Mackler, Alberts, and Bergman 2012).

The Simien Mountains National Park is one of the aforementioned preserved areas with high levels of human disturbance, with a resident human population that relies on subsistence farming and pastoralism. As of 1996, the park supported an estimated 4,500 people within its boundaries, an additional 30,000 people just outside the park, and the crops grown and livestock raised by the local people (Debon- 
net, Melamari, and Bomhard 2006). The human population in and around the park was expected to increase by 1.5-2\% a year (Hurni and Ludi 2000), but there has been no official census since 1996. Tourism within the park has more than tripled from 2004 to 2010, with over 17,500 people visiting in 2010 (Berhanu Gebre, Regional Director, Ethiopian Wildlife Conservation Authority, personal communication, November 17, 2011). In addition, a road built through the park in the late 1990s has increased access to, and vehicular travel through, the park (Hurni and Ludi 2000). This increased overlap in land use by native species, local residents, and tourists inevitably leads to more direct and indirect interactions between humans and wildlife, such as geladas. It is important to address the nature and frequency of these interactions, and whether they affect the very wildlife that aid in making the park so unique and attractive. Some species in the park have clearly been affected, and UNESCO placed the park on the list of World Heritage in Danger in 1996, citing human land use that had degraded the land, depleted resources, and negatively impacted the Walia ibex population (Debonnet, Melamari, and Bomhard 2006).

In order to assess the effect of human presence on geladas, I spent the summer of 2011 in the Simien Mountains National Park addressing three specific levels of interaction (Fig. 1). First, the overlap in resource use (grass consumption) between geladas and livestock may reduce the amount of that resource available in areas where both graze (Dunbar 1978). I quantified the degree of this resource use overlap by measuring the aboveground grass available in areas grazed by both livestock and geladas and comparing it to that available in areas grazed only by geladas. Second, human cultivation of land within gelada ranging areas both reduces the amount of grass present and increases human presence, and thus geladas may change their ranging movements in cultivated areas (Fahrig 2007). I addressed this potential effect by mapping croplands and using hourly gelada movement data acquired through direct observation to determine whether geladas avoid these areas or move through these areas quickly. Finally, direct encounters between geladas and humans or human commensals such as livestock and companion animals may change gelada behavior, for example, by causing flight from the encounter (Beale 2007). In order to understand these encounters, I followed groups of geladas and recorded all such encounters, noting whether the interaction was with a person, domesticated animal, or vehicle; the reaction of the gelada; and when the encounter occurred.

The goal of my research was to determine the nature of the above interactions and use that knowledge to aid the park in conservation efforts. Park policies, such as rules specifying the minimum distance a person should maintain from animals, regulations on foot and vehicular traffic, or restrictions on further development in 


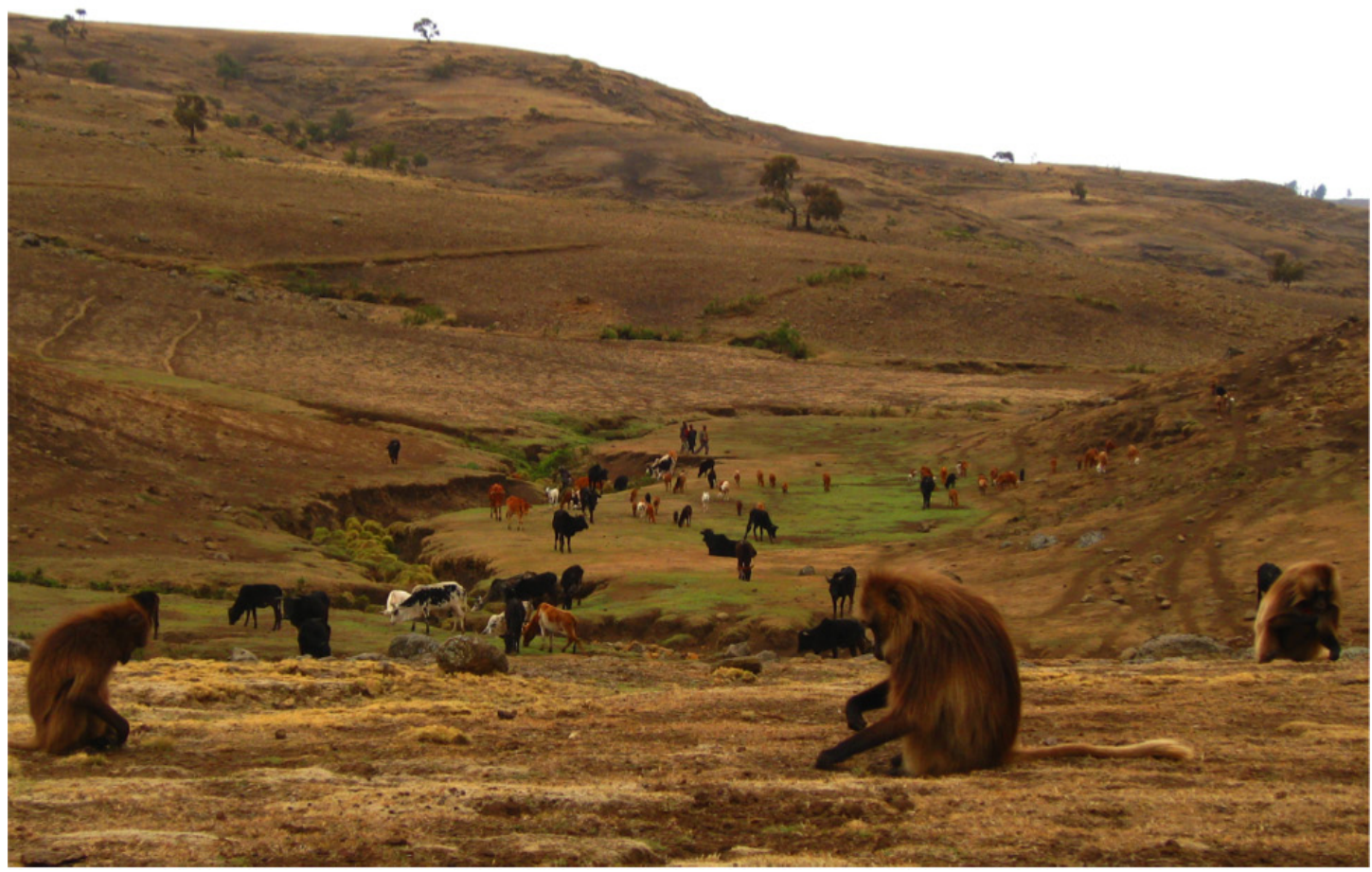

Figure 1: Geladas, grass-eating primates endemic to the highlands of Ethiopia (foreground), encounter many forms of human disturbance in the Simien Mountains National Park, including resource overlap with livestock (foreground), direct interactions with humans (center), and ranging through cultivated land (background).

the park, will be far more effective if based on relevant empirical data. For instance, preliminary results from my study show that geladas encounter vehicles more often than people or domesticated animals, and encounters with vehicles occur mostly in the early morning, when geladas socialize close to the road. Thus, reducing the number of vehicles on the road in the morning could effectively decrease the daily frequency of direct encounters between geladas and humans. The behavioral and resource data I acquired are also applicable beyond just gelada conservation, as most efforts stemming from my research will also serve to protect the other rare and distinctive species that reside and use resources in the park. My research also has the potential to benefit people living within and around the park, by bringing attention to the opportunities that conservation within the park can provide. Other protected areas in Africa have successfully promoted land conservation and wildlife conservation, which attract and protect species adverse to developed areas, which in turn attracts tourists. The jobs created through the resulting tourist industry and park 
maintenance provide an alternative to subsistence farming and pastoralism as well as an incentive to continue promoting conservation (Licht, Slotow, and Millspaugh 2008; Newmark and Hough 2000). In the future, I would like to survey tourists to identify why they come to the park and what they find most memorable when they leave. If tourists visiting and financially supporting the park wish to see more wildlife and less disturbance, the Simien Mountains National Park would have an incentive to successfully implement further conservation measures. The use of behavioral research to support the protection of wildlife species and their coexistence with local people within the park will also strengthen the ties between animal behavior and conservation, paving the way for similar research in the future.

\section{References}

Anthony, Laura L., and Daniel T. Blumstein. 2000. "Integrating Behaviour into Wildlife Conservation: The Multiple Ways That Behaviour Can Reduce Ne." Biological Conservation 95 (3): 303-315. http://dx.doi.org/10.1016/S0006-3207(00)00037-9

Beale, Colin M. 2007. “The Behavioral Ecology of Disturbance Responses." International Journal of Comparative Psychology 20 (2): 111-120.

Beale, Colin M., and Pat Monaghan. 2004. "Human Disturbance: People as Predation-Free Predators?” Journal of Applied Ecology 41 (2): 335-343. http://dx.doi.org/10.1111/j.0021-8901.2004.00900.x

Beehner, Jacinta C., and Colleen McCann. 2008. "Seasonal and Altitudinal Effects on Glucocorticoid Metabolites in a Wild Primate (Theropithecus Gelada)." Physiology \& Behavior 95 (3): 508-514. http://dx.doi.org/10.1016/j.physbeh.2008.07.022

Berger-Tal, Oded, Tal Polak, Aya Oron, Yael Lubin, Burt P. Kotler, and David Saltz. 2011. "Integrating Animal Behavior and Conservation Biology: A Conceptual Framework." Behavioral Ecology 22 (2): 236-239. http://dx.doi.org/10.1093/beheco/arq224

Bergman, Thore J. 2013. "Speech-Like Vocalized Lip-Smacking in Geladas." Current Biology 23 (7): R268-R269. http://dx.doi.org/10.1016/j.cub.2013.02.038

Caro, Tim. 1999. “The Behaviour-Conservation Interface." Trends in Ecology \& Evolution 14 (9): 366-369. http://dx.doi.org/10.1016/S0169-5347(99)01663-8

Davis, Gary E., David M. Graber, and Steven A. Acker. 2004. "National Parks as Scientific Benchmark Standards for the Biosphere; Or, How Are You Going to Tell How It Used to Be, When There's Nothing Left to See?” The George Wright Forum 21 (2): 34-44.

Debonnet, Guy, Lota Melamari, and Bastian Bomhard. 2006. Mission Report: Reactive Monitoring Mission to Simien Mountains National Park Ethiopia 10-17 May 2006.

Dunbar, R. I. M. 1978. "Competition and Niche Separation in a High Altitude Herbivore Community in Ethiopia." African Journal of Ecology 16: 183-199. http://dx.doi.org/10.1111/j.13652028.1978.tb00439.x

Fahrig, Lenore. 2007. "Non-Optimal Animal Movement in Human-Altered Landscapes." Functional Ecology 21 (6): 1003-1015. http://dx.doi.org/10.1111/j.1365-2435.2007.01326.x 
Frid, Alejandro, and Lawrence Dill. 2002. "Human-Caused Disturbance Stimuli as a Form of Predation Risk." Conservation Ecology 6 (1): 11.

Graham, M. D., I. Douglas-Hamilton, W. M. Adams, and P. C. Lee. 2009. "The Movement of African Elephants in a Human-Dominated Land-use Mosaic." Animal Conservation 12 (5): 445-455. http://dx.doi.org/10.1111/j.1469-1795.2009.00272.x

Harmsen, R., J. R. Spence, and W. C. MaHaney. 1991. "Glacial Interglacial Cycles and Development of the Afroalpine Ecosystem on East African Mountains II. Origins and Development of the Biotic Component." Journal of African Earth Sciences 12 (3): 513-523. http://dx.doi. org/10.1016/0899-5362(91)90143-M

Hurni, Hans, and Eva Ludi. 2000. Reconciling Conservation With Sustainable Development. A Participatory Study inside and around the Simen Mountains National Park, Ethiopia. Berne: Centre for Development and Environment.

Indermaur, Lukas, and Benedikt R. Schmidt. 2011. "Quantitative Recommendations for Amphibian Terrestrial Habitat Conservation Derived from Habitat Selection Behavior." Ecological Applications 21 (7): 2548-2554. http://dx.doi.org/10.1890/10-2047.1

Iwamoto, Toshitaka. 1993. "The Ecology of Theropithecus Gelada." In Theropithecus: The Rise and Fall of a Genus, edited by Nina J. Jablonksi, 441-452. New York: Cambridge University Press. http://dx.doi.org/10.1017/CBO9780511565540.017

Kawai, M. 1983. "Social Organization of Gelada Baboons: Social Units and Definitions." Primates 24 (1): 13-24. http://dx.doi.org/10.1007/BF02381450

Kerley, Linda L., John M. Goodrich, Dale G. Miquelle, Evgeny N. Smirnov, Howard B. Quigley, and Maurice G. Hornocker. 2002. "Effects of Roads and Human Disturbance on Amur Tigers." Conservation Biology 16 (1): 97-108. http://dx.doi.org/10.1046/j.1523-1739.2002.99290.x

Licht, Daniel S., Rob Slotow, and Joshua Millspaugh. 2008. "Out of Africa: Lessons from Park Management in South Africa." The George Wright Forum 25 (1): 20-29.

Lusseau, David, David E. Bain, Rob Williams, and Jodi C. Smith. 2009. "Vessel Traffic Disrupts the Foraging Behavior of Southern Resident Killer Whales Orcinus Orca." Endangered Species Research 6: 211-221. http://dx.doi.org/10.3354/esr00154

Malo, Juan E., Pablo Acebes, and Juan Traba. 2011. "Measuring Ungulate Tolerance to Human with Flight Distance: A Reliable Visitor Management Tool?” Biodiversity and Conservation 20 (14): 3477-3488. http://dx.doi.org/10.1007/s10531-011-0136-7

Newmark, William D., and John L. Hough. 2000. "Conserving Wildlife in Africa: Integrated Conservation and Development Projects and Beyond." BioScience 50 (7): 585-592. http:// dx.doi.org/10.1641/0006-3568(2000)050[0585:CWIAIC]2.0.CO;2

Parsons, David J. 2004. "Supporting Basic Ecological Research in U.S. National Parks: Challenges and Opportunities.” Ecological Applications 14 (1): 5-13. http://dx.doi.org/10.1890/035085

Ramirez, Alonso. 2004. "Ecological Research and the Costa Rican Park System." Ecological Applications 14 (1): 25-27. http://dx.doi.org/10.1890/03-5086

Reed, J. Michael. 2002. "Animal Behavior as a Tool in Conservation Biology." In Conservation Medicine: Ecological Health in Practice, edited by A. A. Aguirre, R. S. Ostfeld, C. A. House, and G. M. Tabor, 145-163. New York: Oxford University Press.

Roberts, Eila K., Amy Lu, Thore J. Bergman, and Jacinta C. Beehner. 2012. "A Bruce Effect in Wild Geladas." Science 335 (6073): 1222-1225. http://dx.doi.org/10.1126/science.1213600

Sillero-Zubiri, Claudio, Raman Sukumar, and Adrian Treves. 2007. "Living with Wildlife: The 
Roots of Conflict and the Solutions." In Key Topics in Conservation Biology, edited by D. Macdonald and K. Service, 255-272. Malden, MA: Blackwell Publishing.

Snyder-Mackler, Noah, Susan C. Alberts, and Thore J. Bergman. 2012. "Concessions of an Alpha Male? Cooperative Defence and Shared Reproduction in Multi-Male Primate Groups.” Proceedings. Biological Sciences / The Royal Society 279 (1743):3788-95. http://dx.doi.org/10.1098/ rspb.2012.0842

Snyder-Mackler, Noah, Jacinta C. Beehner, and Thore J. Bergman. 2012. "Defining Higher Levels in the Multilevel Societies of Geladas (Theropithecus gelada)." International Journal of Primatology 33 (5): 1054-1068. http://dx.doi.org/10.1007/s10764-012-9584-5

Stankowich, Theodore. 2008. "Ungulate Flight Responses to Human Disturbance: A Review and Meta-Analysis.” Biological Conservation 141 (9): 2159-2173. http://dx.doi.org/10.1016/j.biocon.2008.06.026

Sutherland, William J. 1998. "The Importance of Behavioural Studies in Conservation Biology." Animal Behaviour 56 (4): 801-809. http://dx.doi.org/10.1006/anbe.1998.0896

Swaisgood, R. 2010. "Conservation and Animal Behavior." Encyclopedia of Animal Behavior. Oxford: Academic Press. http://dx.doi.org/10.1016/B978-0-08-045337-8.00163-7

Swaisgood, Ronald R. 2007. "Current Status and Future Directions of Applied Behavioral Research for Animal Welfare and Conservation." Applied Animal Behaviour Science 102 (3-4): 139-162. http://dx.doi.org/10.1016/j.applanim.2006.05.027

Tuomainen, Ulla, and Ulrika Candolin. 2011. "Behavioural Responses to Human-Induced Environmental Change." Biological Reviews of the Cambridge Philosophical Society 86 (3): 640-57. http://dx.doi.org/10.1111/j.1469-185X.2010.00164.x

Végvári, Zsolt, Zoltán Barta, Pekka Mustakallio, and Tamás Székely. 2011. "Consistent Avoidance of Human Disturbance over Large Geographical Distances by a Migratory Bird.” Biology Letters 7 (6): 814-817. http://dx.doi.org/10.1098/rsbl.2011.0295

Williams, R., and E. Ashe. 2007. "Killer Whale Evasive Tactics Vary with Boat Number." Journal of Zoology 272 (4): 390-397. http://dx.doi.org/10.1111/j.1469-7998.2006.00280.x

Williams, Rob, David Lusseau, and Philip S. Hammond. 2006. "Estimating Relative Energetic Costs of Human Disturbance to Killer Whales (Orcinus Orca).” Biological Conservation 133 (3): 301-311. http://dx.doi.org/10.1016/j.biocon.2006.06.010

Yihune, Mesele, Afework Bekele, and Zelealem Tefera. 2008. "Human-Ethiopian Wolf Conflict in and around the Simien Mountains National Park, Ethiopia." International Journal of Ecology and Environmental Sciences 34 (2): 149-155. 